\title{
Apigenin induces caspase-dependent apoptosis by inhibiting signal transducer and activator of transcription 3 signaling in HER2-overexpressing SKBR3 breast cancer cells
}

\author{
HYE-SOOK SEO ${ }^{1}$, JIN MO KU ${ }^{1}$, HAN-SEOK CHOI ${ }^{1}$, JONG-KYU WOO $^{2}$, \\ BO-HYOUNG JANG ${ }^{1}$, HOYEON GO ${ }^{3}$, YONG CHEOL SHIN ${ }^{1}$ and SEONG-GYU KO ${ }^{1}$
}

${ }^{1}$ Laboratory of Clinical Biology and Pharmacogenomics and Center for Clinical Research and Genomics, College of Korean Medicine, Kyung Hee University, Dongdaemun-gu, Seoul 130-701; ${ }^{2}$ College of Pharmacy, Gachon University of Medicine and Science, Yeonsu-gu, Incheon 406-840; ${ }^{3}$ Department of Oriental Medicine, Semyung University, College of Korean Medicine, Jecheon, Chungbuk 390-711, Republic of Korea

Received May 2, 2014; Accepted January 21, 2015

DOI: $10.3892 / \mathrm{mmr} .2015 .3698$

\begin{abstract}
Phytoestrogens have been demonstrated to inhibit tumor induction; however, their molecular mechanisms of action have remained elusive. The present study aimed to investigate the effects of a phytoestrogen, apigenin, on proliferation and apoptosis of the human epidermal growth factor receptor 2 (HER2)-expressing breast cancer cell line SKBR3. Proliferation assay, MTT assay, fluorescence-activated cell sorting analysis, western blot analysis, immunocytochemistry, reverse transcription-polymerase chain reaction and ELISA assay were used in the present study. The results of the present study indicated that apigenin inhibited the proliferation of SKBR3 cells in a dose- and time-dependent manner. This inhibition of growth was accompanied by an increase in the sub- $G_{0} / G_{1}$ apoptotic population. Furthermore, apigenin enhanced the expression levels of cleaved caspase- 8 and -3 , and induced the cleavage of poly(adenosine diphosphate ribose) polymerase in SKBR3 cells, confirming that apigenin promotes apoptosis via a caspase-dependent pathway. Apigenin additionally reduced the expression of phosphorylated (p)-janus kinase 2 and p-signal transducer and activator of transcription 3 (STAT3), inhibited $\mathrm{CoCl}_{2}$-induced vascular endothelial growth factor (VEGF) secretion and decreased the nuclear localization of STAT3. The STAT3 inhibitor S31-201 decreased the cellular proliferation rate and reduced the expression of p-STAT3 and
\end{abstract}

Correspondence to: Professor Seong-Gyu Ko, Laboratory of Clinical Biology and Pharmacogenomics and Center for Clinical Research and Genomics, College of Korean Medicine, Kyung Hee University, 26 Kyungheedae-ro, Dongdaemun-gu, Seoul 130-701, Republic of Korea

E-mail: epiko@khu.ac.kr

Key words: breast cancer, human epidermal growth factor receptor 2, apigenin, apoptosis, signal transducer and activator of transcription 3, vascular endothelial growth factor
VEGF. Therefore, these results suggested that apigenin induced apoptosis via the inhibition of STAT3 signaling in SKBR3 cells. In conclusion, the results of the present study indicated that apigenin may be a potentially useful compound for the prevention or treatment of HER2-overexpressing breast cancer.

\section{Introduction}

Apigenin (4',5,7-trihydroxyflavone) is a non-toxic dietary flavonoid present in numerous herbs, including parsley, thyme, peppermint, chamomile, horsetail herb, lemon balm, perilla, vervain and yarrow (1). Apigenin has been demonstrated to exert anti-oxidant (1), anti-inflammatory (2), anti-telomerase (3) and anti-depressant activities (4). Of note, apigenin also possesses anti-tumor properties and is therefore of particular interest in the development of novel drugs for the treatment and/or prevention of cancer $(5,6)$. It has previously been demonstrated that apigenin is able to reduce the volume and mass of implanted androgen-sensitive 22Rv1 and androgen-insensitive PC-3 tumor cells (7). Furthermore, apigenin suppresses inducible cyclooxygenase and nitric oxide synthase in mouse macrophages (8), and inhibits ultraviolet light-induced skin carcinogenesis in SKH-1 mice (9). Apigenin has also been shown to inhibit growth and induce apoptosis in numerous cancer cell lines, including those of breast (10), lung (11), colon (12,13), prostate (14), leukemia (15) and pancreatic cancer (16).

Apoptosis, also known as programmed cell death, is a fundamental physiological process, required for normal development and tissue homeostasis $(17,18)$. Apoptotic progression is associated with various caspases, which comprise a group of aspartate-specific cysteine proteases, which are members of the interleukin-1-converting enzyme family $(17,18)$. The caspase cascade signaling pathway has crucial roles in the induction, transduction and amplification of intracellular apoptotic signals $(17,18)$. In the majority of tumor cells, apoptosis is induced via two distinct signaling pathways: The extrinsic and intrinsic apoptotic pathways. The extrinsic pathway is associated with the activation of death receptors, including Fas and the tumor necrosis factor receptors, and the cleavage of caspase- 8 
and caspase-3 (19-21). The intrinsic pathway is associated with the cleavage of caspase- 9 and -3 , as well as alterations in the mitochondrial membrane potential and the mitochondrial permeability transition (22). Caspase-3 is responsible for the cleavage of poly(adenosine diphosphate-ribose) polymerase (PARP) during cell death in each of these pathways (23).

Overexpression of the human epidermal growth factor receptor 2 (HER2) tyrosine kinase is associated with the pathogenesis and aggressive characteristics underlying $25 \%$ of invasive human breast cancers (24). Clinical and experimental evidence has suggested that aberrant HER2 signaling may contribute to the initiation of tumor development and disease progression (24). HER2-positive tumors are associated with more aggressive phenotypes, characterized by more frequent recurrence and shorter overall survival, compared with that of HER2-negative tumor subtypes (25). The recombinant humanized anti-HER 2 monoclonal antibody trastuzumab (herceptin) is frequently used in the treatment of patients with HER-2-overexpressing subtypes of cancer (26). Trastuzumab induces downregulation of HER2/Neu, resulting in the disruption of receptor dimerization and signaling (27). Trastuzumab also induces cell cycle arrest during $\mathrm{G}_{1}$ phase and inhibits the phosphorylation of p27Kip1, suppressing cdk2 activity and reducing proliferation (28). Trastuzumab suppresses angiogenesis via the induction of anti-angiogenic factors and the repression of pro-angiogenic factors. However, numerous patients with breast cancer are unresponsive to trastuzumab treatment or develop a resistance to this drug (29). There have therefore been numerous studies devoted to the identification of alternative compounds with the ability to effectively treat HER2-overexpressing subtypes of breast cancer.

Previously, our group reported that apigenin promoted apoptosis via the extrinsic pathway, inducing p53 and inhibiting STAT3 and NFKB signaling in HER2-transfected MCF-7 cells (30). The present study aimed to investigate whether apigenin exerted growth-suppressive activity in natural HER2-overexpressing breast cancer cells, using the SKBR3 cell line. The effects of apigenin on the proliferation and apoptosis of SKBR3 cells were therefore evaluated. Thyroid cancer cells were also used for comparison, in order to demonstrate that the effect of apigenin was not cell-specific. The mechanism underlying the regulation of SKBR3 cell growth by apigenin was also investigated, by analysis of the cell cycle and determination of the expression levels of apoptotic and intracellular signaling molecules. In addition, whether apigenin was able to inhibit the STAT3 signaling pathway, resulting in growth suppression of HER2-overexpressing breast cancer cells was examined.

\section{Materials and methods}

Compounds. Apigenin (4',5,7-trihydroxyflavone) genistein and quercetin were purchased from Sigma-Aldrich (St. Louis, MO, USA). Apigenin was dissolved in dimethyl sulfoxide (DMSO), and the final concentration of DMSO in the controls and each sample did not exceed $0.1 \%$. It was found that $0.1 \%$ DMSO did not influence the cell growth rate compared with 0\% DMSO (no treatment) in the breast cancer cells (data not shown). The caspase-8 inhibitor Z-IETD-fmk and the caspase-9 inhibitor Z-LEHD-fmk were obtained from R\&D Systems, Inc. (Minneapolis, MN, USA). The STAT3 inhibitor S31-201 was obtained from Calbiochem (Billerica, MA, USA) and an EZ-western chemiluminescent detection kit was purchased from Daeillab Service Co. (Seoul, Korea).

Cell culture. The human breast cancer cell line SKBR3 (American Type Culture Collection, Manassas, VA, USA) was cultured in Dulbecco's modified Eagle's medium (Life Technologies Korea LLC, Seoul, Korea) containing $50 \mathrm{U} / \mathrm{ml}$ penicillin, $50 \mathrm{mg} / \mathrm{ml}$ streptomycin and $10 \%$ fetal bovine serum (FBS; Welgene, Daegu, Korea) at $37^{\circ} \mathrm{C}$ in an atmosphere of $5 \% \mathrm{CO}_{2}$. The human thyroid cancer cell lines SNU790 and SNU80 were obtained from the Korean Cell Line Bank (Seoul, Korea) and cultured in RPMI (Life Technologies Korea LLC) containing $50 \mathrm{U} / \mathrm{ml}$ penicillin, $50 \mathrm{mg} / \mathrm{ml}$ streptomycin (Life Technologies Korea LLC) and $10 \%$ FBS at $37^{\circ} \mathrm{C}$ in an atmosphere of $5 \% \mathrm{CO}_{2}$.

Antibodies. Primary antibodies against cleaved caspase- 8 (9496) and PARP (9542), were purchased from Cell Signaling Technology, Inc. (Danvers, MA, USA). Primary antibodies against B cell lymphoma 2(BCL2; sc-7382),BCL2-associated X (BAX; sc-7480), p53 (sc-126) and hypoxia-inducible factor (Hif)-1 $\alpha$ (sc-13515) were obtained from Santa Cruz Biotechnology, Inc. (Dallas, TX, USA). Primary antibodies against STAT3 (06-596), p-STAT3 (Tyr705; 05-485), vascular endothelial growth factor (VEGF; 05-1116) and p-janus kinase 2 (JAK2, Tyr1022/Tyr1023; 06-255) were obtained from EMD-Millipore (Billerica, MA, USA). The anti-tubulin antibody (T3526) was from Sigma-Aldrich. Horseradish peroxidase (HRP)-conjugated secondary antibodies (mouse and rabbit) were purchased from Calbiochem (San Diego, CA, USA) and the anti-goat secondary antibody was from Jackson ImmunoResearch Laboratories, Inc. (West Grove, PA, USA).

Cell proliferation assay. Cells were seeded in 12-well culture plates at a density of $5 \times 10^{4}$ cells/well. After the cells were exposed to various concentrations of apigenin genistein or quercetin $(0,20,40,60,80$ or $100 \mu \mathrm{M})$ and incubated at $37^{\circ} \mathrm{C}$ for three days, the cells were harvested by trypsinization (Sigma-Aldrich), resuspended in 1-2 ml medium, and counted using a hemocytometer (Sigma-Aldrich).

MTT assay. Cells were seeded in 96-multiwell culture plates at a density of $2 \times 10^{3}-3 \times 10^{3}$ cells/well and incubated for $24 \mathrm{~h}$ at $37^{\circ} \mathrm{C}$. Subsequently, the cells were treated with different concentrations of apigenin $(0-80 \mu \mathrm{M})$ for 24,48 or $72 \mathrm{~h}$. Following incubation, MTT reagent $(0.5 \mathrm{mg} / \mathrm{ml})$ was added to each well, and the plates were incubated in the dark at $37^{\circ} \mathrm{C}$ for $2 \mathrm{~h}$. At the end of the incubation, the medium was removed, the resulting formazan was dissolved in DMSO, and the optical density was measured at $570 \mathrm{~nm}$ using an ELISA plate reader (Gemini EM Microplate reader, Versa Max; Molecular Devices, Sunnyvale, CA, USA).

Cell cycle analysis by flow cytometry. Cells were harvested with $0.25 \%$ trypsin and washed once with phosphate-buffered saline (PBS). Following centrifugation, the cells were fixed in cold $95 \%$ ethanol with $0.5 \%$ Tween- 20 and stored at $-20^{\circ} \mathrm{C}$ for at least $30 \mathrm{~min}$. The cells were incubated in $50 \mu \mathrm{g} / \mathrm{ml}$ propidium iodide [PI (Sigma-Aldrich), including 1\% sodium citrate 

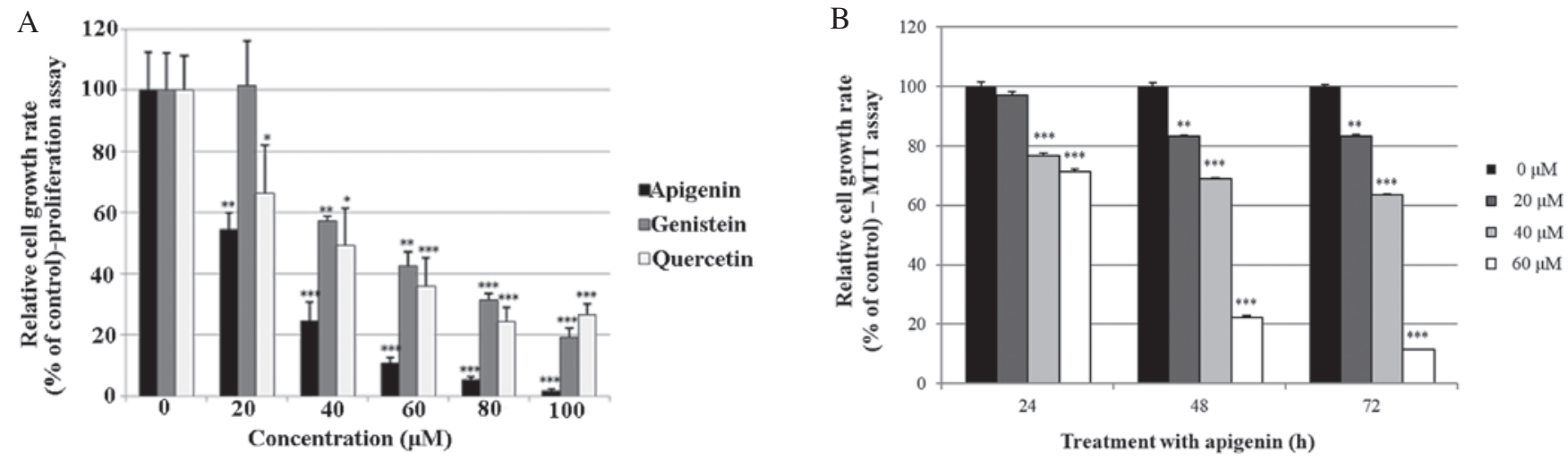
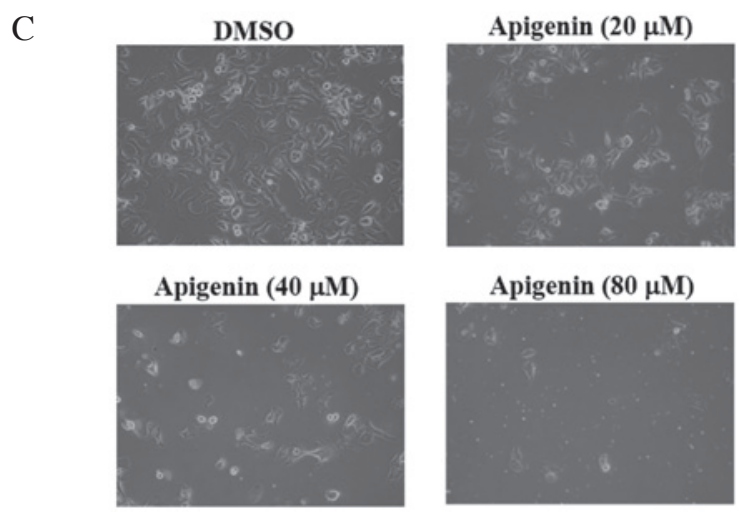

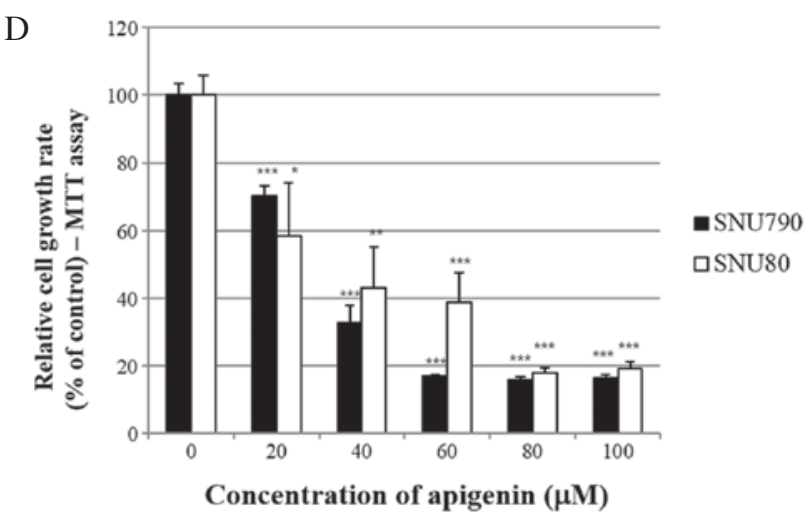

Figure 1. Effect of apigenin on cancer cell growth. (A) SKBR3 cells were treated with various doses of apigenin, genistein and quercetin (0, 20, 40, 60, 80 or $100 \mu \mathrm{M})$. Following $72 \mathrm{~h}$ of culture, cell viability was assessed using a cell proliferation assay. (B) SKBR3 cells were treated with various doses of apigenin ( 0 , $20,40$ or $60 \mu \mathrm{M})$ and the relative cell growth rate was measured by MTT assay following 24, 48 and $72 \mathrm{~h}$ of culture. The growth rate of the vehicle-treated cells was set to $100 \%$, and the relative decrease in cell viability resulting from the apigenin treatment was expressed as a percentage of the control. (C) SKBR3 cells were treated with various doses of apigenin $(0,20,40$ or $80 \mu \mathrm{M})$ for $72 \mathrm{~h}$ and photographed by phase contrast microscopy (magnification, $\mathrm{x} 40)$. Control cells were treated with DMSO alone. (D) SNU790 and SNU80 human thyroid cancer cell lines were treated with various doses of apigenin (0, 20, 40, 60, 80 or $100 \mu \mathrm{M}$ ). The relative cell growth rate was measured by MTT assay following $72 \mathrm{~h}$ of culture. The growth rate of the vehicle-treated cells was set to $100 \%$, and the relative decrease in cell viability resulting from the apigenin treatment was expressed as a percentage of the control. Values are presented as the mean \pm standard deviation of three independent experiments $\left({ }^{*} \mathrm{P}<0.05,{ }^{* *} \mathrm{P}<0.01,{ }^{* * * *} \mathrm{P}<0.001\right.$, as compared with $0 \mu \mathrm{M}$ treated cells). DMSO, dimethyl sulfoxide.

(Sigma-Aldrich) and $50 \mu \mathrm{g} / \mathrm{ml}$ RNase A (Sigma-Aldrich)] at room temperature in the dark for $30 \mathrm{~min}$. Analysis of the apoptotic cells was performed with a FACScan flow cytometer (Becton Dickinson, Mountain View, CA, USA), and the data were analyzed using CellQuest software (BD Biosciences, San Jose, CA, USA).

Immunocytochemistry. Cells $\left(4 \times 10^{4}\right.$ cells/well) were seeded in eight-well chamber slides, incubated for $24 \mathrm{~h}$ at $37^{\circ} \mathrm{C}$ and treated with apigenin $(40 \mu \mathrm{M})$ in the presence or absence of $\mathrm{CoCl}_{2}$ (Sigma-Aldrich) for a further $24 \mathrm{~h}$. The cells were fixed with $4 \%$ paraformaldehyde (Sigma-Aldrich) for $30 \mathrm{~min}$ and treated with $3 \%$ hydrogen peroxide $\left(\mathrm{H}_{2} \mathrm{O}_{2}\right.$; Sigma-Aldrich) in methanol for 20 min to quench the endogenous peroxidase activity. The cells were washed with PBS, blocked with $5 \%$ bovine serum albumin in PBS for $1 \mathrm{~h}$ and incubated with the anti-STAT3 primary antibody (1:200 dilution) overnight at $4^{\circ} \mathrm{C}$. After washing with PBS, the cells were incubated with the anti-rabbit biotin-conjugated secondary antibody for $1 \mathrm{~h}$ at room temperature. Subsequently, the cells were treated with Vectastain ABC reagent (Vector Laboratories, Inc. Burlingame, CA, USA) for $30 \mathrm{~min}$ at $4^{\circ} \mathrm{C}$ and stained with diaminobenzidine tetrachloride (DAB; Thermo Fisher Scientific, Waltham, MA, USA) and hematoxylin (Sigma-Aldrich). The cells were mounted with mounting medium (Vector Laboratories, Inc., Burlingame,
CA, USA) and subsequently analyzed by microscopy (CKX41; Olympus America Inc., Center Valley, PA, USA).

Measurement of VEGF secreted from SKBR3 cells by ELISA. To assess the level of VEGF in the SKBR3 cell supernatants, the cells were treated with apigenin $(0-80 \mu \mathrm{M})$ in the presence or absence of $\mathrm{CoCl}_{2}(100 \mu \mathrm{M})$ to mimic hypoxia. After $24 \mathrm{~h}$, the media were collected, centrifuged at $15,000 \mathrm{x} \mathrm{g}$ at room temperature to remove the cellular debris, and stored at $-70^{\circ} \mathrm{C}$ until assayed for VEGF. The amount of VEGF secreted into the culture medium was measured by ELISA according to the manufacturer's instructions (Human VEGF Quantikine ELISA kit; R\&D Systems, Minneapolis, MN, USA). Briefly, 96-well plates were coated with capture antibody in ELISA coating buffer and incubated overnight at $4^{\circ} \mathrm{C}$. The plates were then washed with PBS with $0.05 \%$ Tween 20 (PBS-T) and subsequently blocked with $10 \%$ FBS in PBS for $1 \mathrm{~h}$ at $20^{\circ} \mathrm{C}$. Serial dilutions of standard antigen or sample in dilution buffer (10\% FBS in PBS) were added to the plates, and the plates were incubated for $2 \mathrm{~h}$ at $20^{\circ} \mathrm{C}$. Following washing, biotin-conjugated anti-mouse immunoglobulin E and streptavidin-conjugated horseradish peroxidase (SAv-HRP) (R\&D Systems, Inc.) were added to the plates, and the plates were incubated for $1 \mathrm{~h}$ at $20^{\circ} \mathrm{C}$. Finally, the tetramethylbenzidine (TMB) substrate was added to the plates, and after $15 \mathrm{~min}$ of incubation in the dark, $2 \mathrm{~N} \mathrm{H}_{2} \mathrm{SO}_{4}$ was 
A
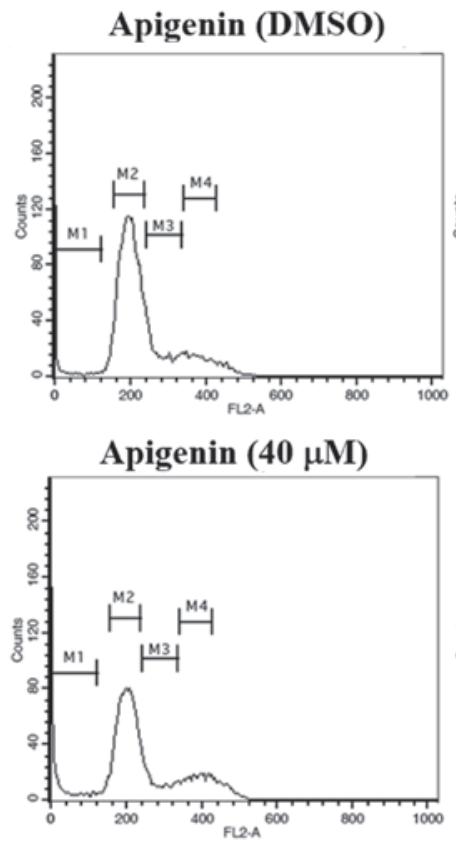

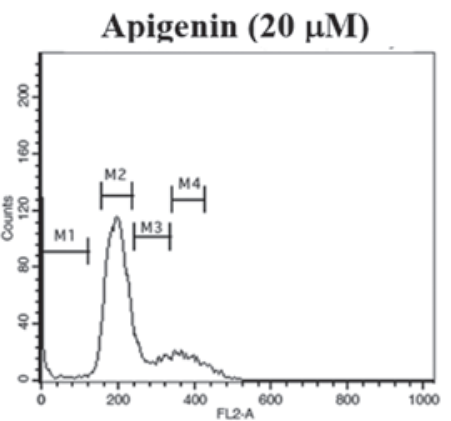

Apigenin $(80 \mu \mathrm{M})$

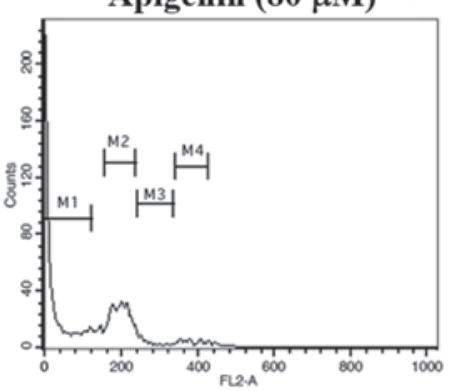

B

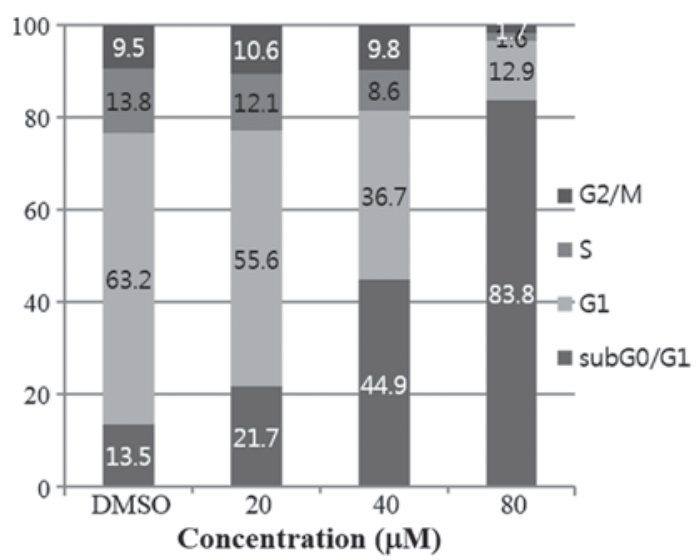

Figure 2. Effect of apigenin on the cell cycle and sub $\mathrm{G}_{0} / \mathrm{G}_{1}$ apoptotic population of SKBR3 cells. (A) SKBR3 cells were treated with apigenin ( 0 , 20 , 40 or $80 \mu \mathrm{M}$ ) and fixed $72 \mathrm{~h}$ later for flow cytometric analysis. Propidium iodide-labeled nuclei were analyzed for DNA content. (B) The sub $\mathrm{G}_{0} / \mathrm{G}_{1}$ apoptotic population and the $\mathrm{G}_{1}, \mathrm{~S}$ and $\mathrm{G}_{2} / \mathrm{M}$ phase populations were quantified using DNA histograms. Values shown are representative of three independent experiments that produced similar results. DMSO, dimethly sulfoxide.

A

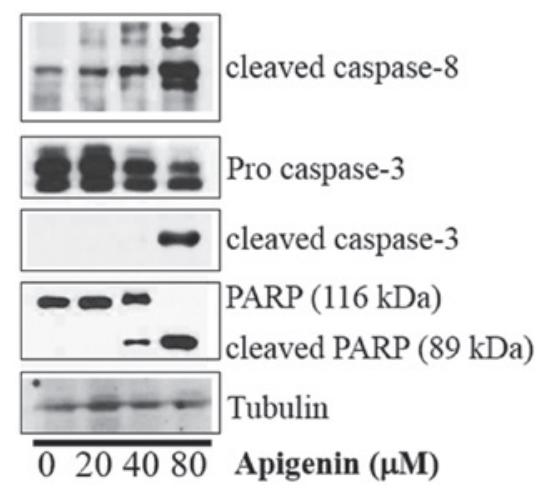

B

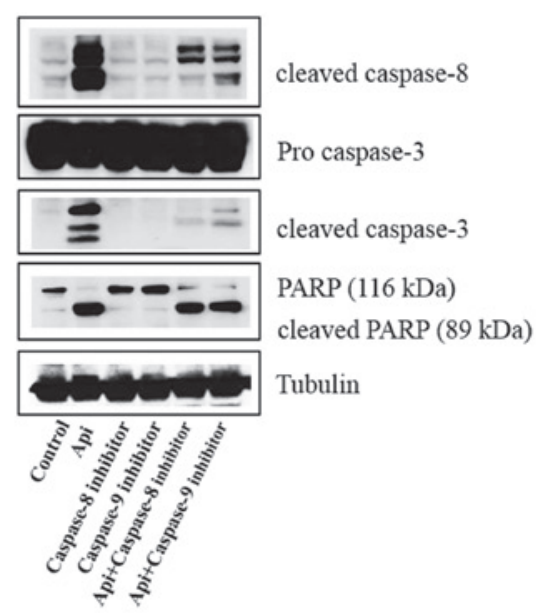

C

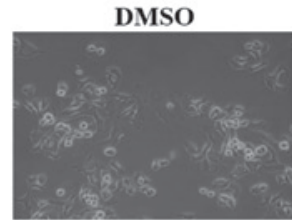

caspase- 8 inhibitor

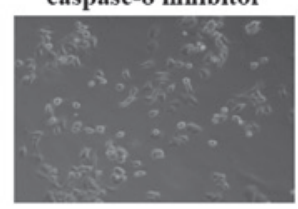

caspase-9 inhibitor

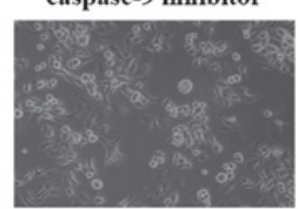

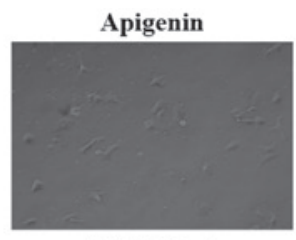

Apigenin +

caspase-8 inhibitor

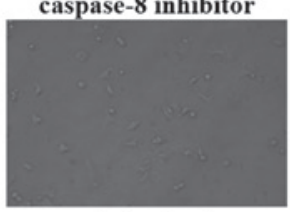

Apigenin + caspase-9 inhibitor

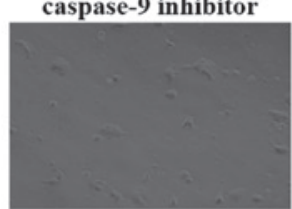

Figure 3. Effect of apigenin on the expression of apoptotic molecules in SKBR3 cells. (A) Apigenin induces apoptosis via a caspase-dependent apoptotic pathway in SKBR3 cells. SKBR3 cells were treated with apigenin $(0,20,40$ or $80 \mu \mathrm{M})$ for $24 \mathrm{~h}$. Whole-cell lysates were evaluated by western blot analysis with anti-cleaved caspase-8, anti-cleaved caspase-3, anti-PARP and anti-tubulin antibodies. Blots are representatives of three independent experiments that produced similar results. (B) Effect of caspase- 8 and caspase- 9 inhibitors on apigenin-induced apoptosis in SKBR 3 cells. SKBR3 cells were exposed to $80 \mu \mathrm{M}$ apigenin with or without caspase- 8 inhibitor $(40 \mu \mathrm{M})$ or caspase- 9 inhibitor $(40 \mu \mathrm{M})$ for $24 \mathrm{~h}$, the cell lysates were separated by SDS-PAGE, and western blot analysis with specific antibodies was performed (anti-cleaved caspase-8, anti-cleaved caspase-3, anti-cleaved PARP and anti-tubulin). Results displayed are representative of three independent experiments that produced similar results. (C) Effect of caspase- 8 and caspase-9 inhibitors on SKBR3 cell proliferation. SKBR3 cells were exposed to $80 \mu \mathrm{M}$ apigenin in the presence or absence of caspase- 8 inhibitor $(40 \mu \mathrm{M})$ or caspase-9 inhibitor $(40 \mu \mathrm{M})$ for $72 \mathrm{~h}$ and photographed by phase contrast microscopy (magnification, x40). DMSO, dimethyl sulfoxide; PARP, poly(adenosine diphosphate-ribose) polymerase; Api, apigenin.

added to stop the reaction. The optical density was measured at $450 \mathrm{~nm}$ on the automated ELISA reader (Molecular Devices).

Western blot analysis. Cells were lysed in modified radioimmunoprecipitation assay buffer $[150 \mathrm{mM} \mathrm{NaCl}, 1 \% \mathrm{NP}-40$,
$0.5 \%$ deoxycholate, $0.1 \%$ SDS, $50 \mathrm{mM}$ Tris ( $\mathrm{pH} 8.0), 1 \mathrm{mM}$ EDTA, $1 \mathrm{mM}$ phenylmethylsulfonyl fluoride, $1 \mathrm{mM} \mathrm{NaF}, 1 \mathrm{mM}$ $\mathrm{Na}_{3} \mathrm{VO}_{4}$ and a protease inhibitor mixture] (Life Technologies Korea LLC). The lysates were cleared by centrifugation at $10,000 \mathrm{xg}$ for $15 \mathrm{~min}$, and the supernatants were collected. 


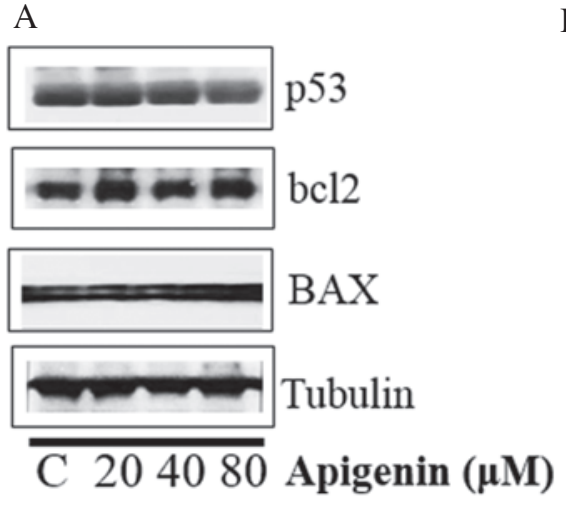

B

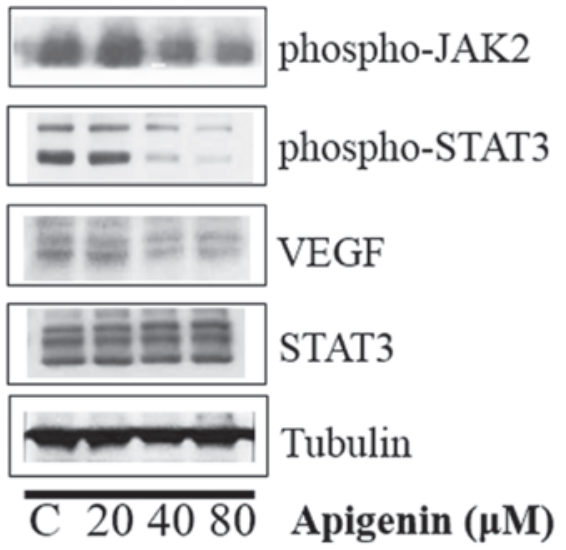

C

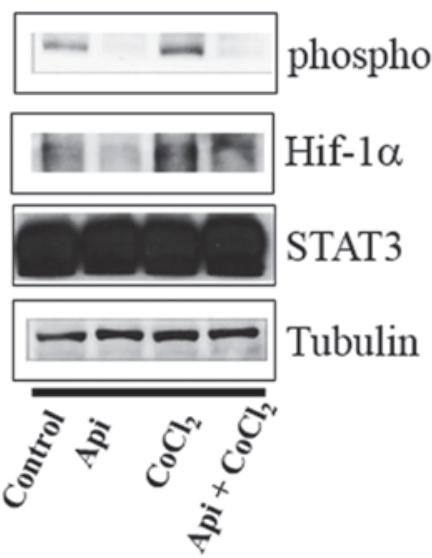

Figure 4. Effect of apigenin on STAT3 activation in SKBR3 cells. (A) SKBR3 cells were treated with apigenin ( $0-80 \mu \mathrm{M})$ for $24 \mathrm{~h}$. Whole-cell lysates were analyzed by western blotting with anti-p53, anti-bcl2, anti-BAX and anti-tubulin antibodies. (B) SKBR3 cells were treated with apigenin $(0-80 \mu \mathrm{M})$ for $24 \mathrm{~h}$. Whole-cell lysates were analyzed by western blotting with anti-phospho-JAK2, anti-phospho-STAT3, anti-VEGF, anti-STAT3, and anti-tubulin antibodies. (C) SKBR3 cells were treated with apigenin $(80 \mu \mathrm{M})$ for $24 \mathrm{~h}$ in the presence or absence of $\mathrm{CoCl}_{2}(4 \mathrm{~h})$. Whole-cell lysates were analyzed by western blotting with anti-phospho-STAT3, anti-HIF-1 $\alpha$, anti-STAT3, and anti-tubulin antibodies. Blots shown are representative of three independent experiments that gave similar results. STAT3, signal transducer and activator of transcription 3; VEGF, vascular endothelial growth factor; bcl2, B-cell lymphoma 2; BAX, bc12-like protein 4; JAK2, janus kinase 2; HIF-1 $\alpha$, hypoxia inducible factor-1 $\alpha$.

The protein concentration was quantified using a Bradford Protein Assay (Bio-Rad, Hercules, CA, USA). Equal amounts of protein lysates were used for western blot analysis with the indicated antibodies (primary antibody, 1:1,000 dilution, $4^{\circ} \mathrm{C}$; secondary antibody, 1:3,000 dilution, room temperature). The immunoreactive protein bands were detected using an EZ-Western Detection kit (Daeillab Service Co., Seoul, Korea).

Statistical analysis. All experiments were performed in triplicate. Results of the cell proliferation assay and MTT assay are expressed as the mean \pm standard deviation. The standard deviations for all of the measured biological parameters are displayed in the appropriate figures. A Student's t-test (Microsoft Excel, Albuquerque, NM, USA) was used for single variable comparisons, and $\mathrm{P}<0.05$ was considered to indicate a statistically significant difference.

\section{Results}

Apigenin suppresses the growth of SKBR3 cells. The growth suppressive activity of three phytoestrogens (apigenin, genistein and quercetin) was evaluated in SKBR3 cells using a cell proliferation assay. As indicated in Fig. 1A, apigenin, genistein and quercetin significantly inhibited SKBR3 cell proliferation in a dose-dependent manner $(0-100 \mu \mathrm{M})$ following $72 \mathrm{~h}$ of treatment. Among the three phytoestrogens, apigenin exerted the greatest growth suppressive activity in the SKBR3 cells. Therefore, apigenin was selected for use in the present study. In addition, the time-dependent growth suppressive activity of apigenin was measured by MTT assay, as shown in Fig. 1B. It was demonstrated that the proliferation assay was more sensitive than the MTT assay with respect to measuring the extent of cell growth inhibition, as indicated by the comparison between Fig. 1A and B. Furthermore, the growth inhibition exerted by apigenin was confirmed by microscopic cellular evaluation. The results in Fig. $1 C$ demonstrated that apigenin was able to effectively attenuate the growth of SKBR3 monolayer cells following $72 \mathrm{~h}$ of treat-
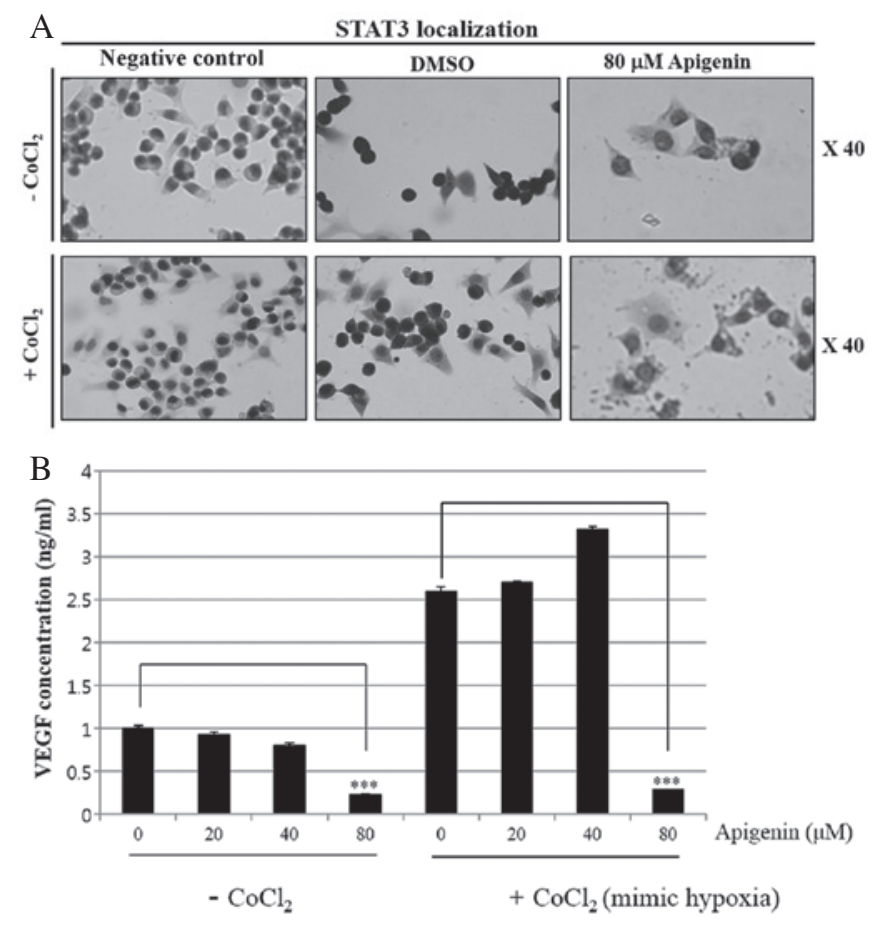

Figure 5. Effect of apigenin on STAT3 nuclear localization and VEGF production in SKBR3 cells. (A) SKBR3 cells were treated with apigenin $(80 \mu \mathrm{M})$ for $24 \mathrm{~h}$ in the presence or absence of $\mathrm{CoCl}_{2}$ and subsequently subjected to immunocytochemical analysis for the detection of nuclear STAT3. Nuclear localization of STAT3 was decreased in the apigenin-treated group. Images shown are representative of three independent experiments that produced similar results. Magnification, $\mathrm{x} 40$ (B) SKBR3 cells were treated with apigenin $(0,20,40$ or $80 \mu \mathrm{M})$ for $24 \mathrm{~h}$ in the presence or absence of $\mathrm{CoCl}_{2}$, and the VEGF concentration was determined by ELISA. Values are expressed as the mean \pm standard deviation. ${ }^{* * *} \mathrm{P}<0.001$. STAT3, signal transducer and activator of transcription 3; VEGF, vascular endothelial growth factor; DMSO, dimethyl sulfoxide.

ment. Of note, apigenin also induced morphological changes in these cells (Fig. 1C). Furthermore, the growth suppressive activity of apigenin was not limited to breast cancer cells. The results presented in Fig. 1D demonstrated that apigenin 

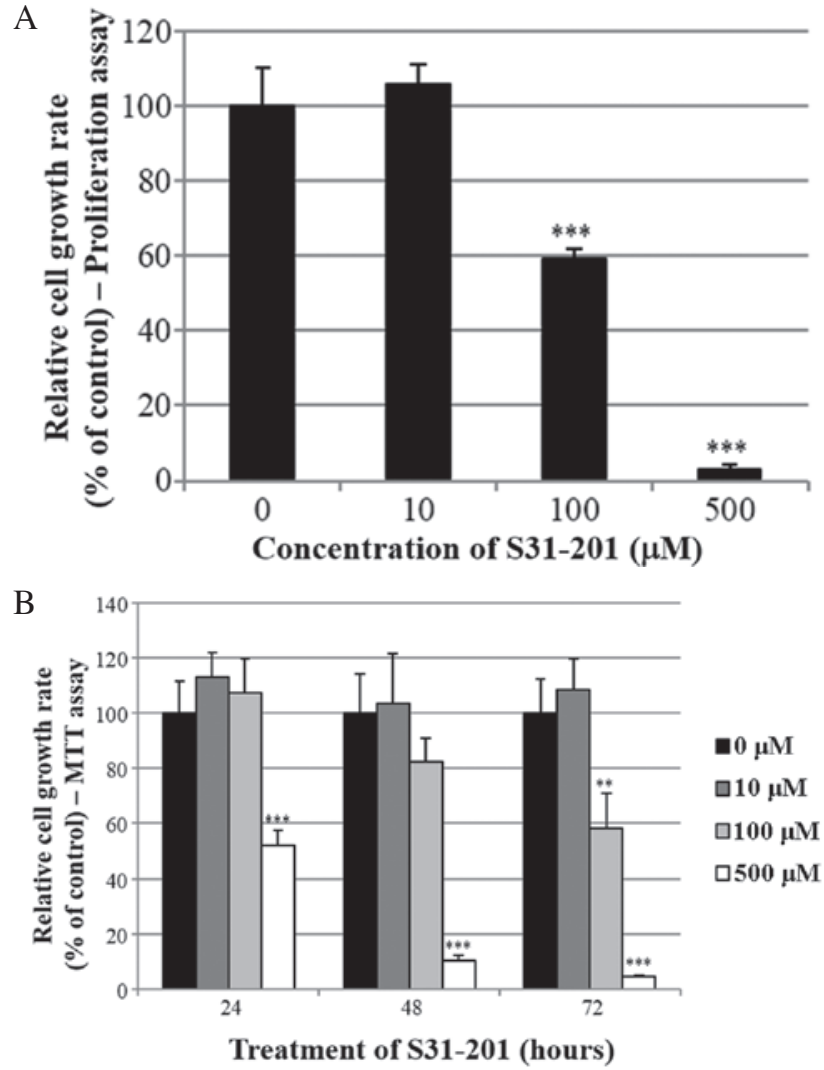

$\mathrm{C}$

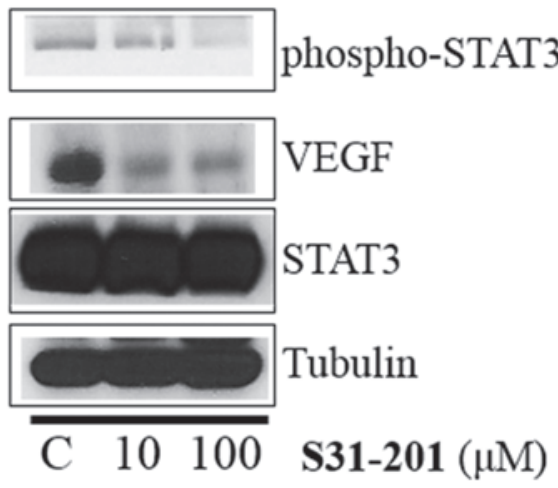

Figure 6. Effect of STAT3 inhibitor S31-201 on the growth of SKBR3 cells. SKBR3 cells were treated with various doses $(10,100$ or $500 \mu \mathrm{M})$ of the STAT3 inhibitor S31-201. (A) After $72 \mathrm{~h}$, cell viability was assessed using a cell proliferation assay. (B) The relative cell growth rate was measured by MTT assay after 24, 48 and $72 \mathrm{~h}$. The growth rate of the vehicle-treated cells was set as $100 \%$, and the relative decrease in the cell viability following S31-201 treatment was expressed as a percentage of the control. Values are expressed as the mean \pm standard deviation. ${ }^{* *} \mathrm{P}<0.01,{ }^{* * *} \mathrm{P}<0.001$. (C) SKBR3 cells were treated with STAT3 inhibitor S31-201 for $24 \mathrm{~h}$. Whole-cell lysates were analyzed by western blotting with anti-phospho-STAT3, anti-STAT3, anti-VEGF and anti-tubulin antibodies. Blots shown are representative of three independent experiments that produced similar results. STAT3, signal transducer and activator of transcription 3; VEGF, vascular endothelial growth factor.

also inhibited the growth of papillary and anaplastic thyroid cancer cells (SNU790 and SNU80).

Growth-suppressive activity of apigenin is accompanied by an increase in the sub $G_{0} / G_{1}$ apoptotic population in SKBR3 cells. To investigate whether apigenin inhibited cell proliferation via the induction of alterations in cell cycle progression, the effects of apigenin on the cell cycle were evaluated in SKBR3 cells. Cells were treated with apigenin $(0-80 \mu \mathrm{M})$ for $72 \mathrm{~h}$ and cell

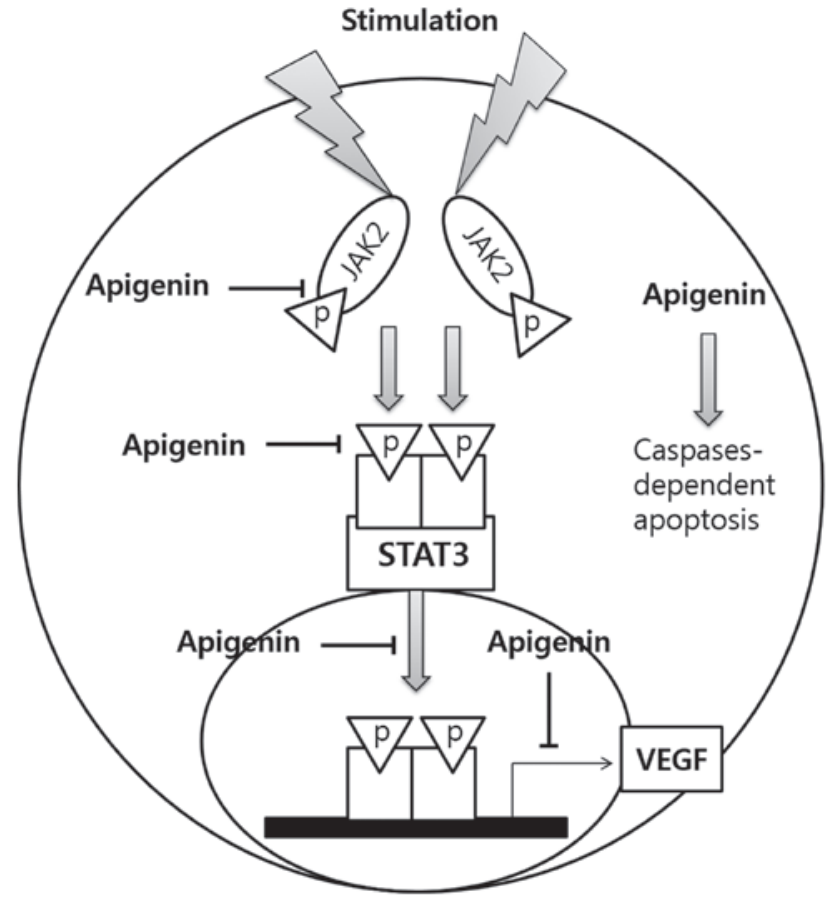

Figure 7. Molecular mechanism of apigenin. STAT3, signal transducer and activator of transcription 3; VEGF, vascular endothelial growth factor; JAK2, janus kinase 2; p, phosphorylated.

cycle distribution was determined by flow cytometric analysis. The results demonstrated that apigenin induced an increase in the sub $\mathrm{G}_{0} / \mathrm{G}_{1}$ apoptotic population in SKBR3 cells (Fig. 2).

Apigenin induces apoptosis via caspase-dependent pathways in SKBR3 cells. Whether apigenin activated caspase-dependent apoptosis was assessed via evaluation of the expression levels of caspase- 8 , caspase- 3 and PARP. It was revealed that apigenin upregulated the expression levels of cleaved caspase- 8 and -3 , and induced PARP cleavage in SKBR3 cells (Fig. 3A). It was also demonstrated that the cleavage of caspase- 8 , caspase- 3 and PARP was inhibited by the caspase- 8 inhibitor Z-IETD- $f m k$ and the caspase-9 inhibitor Z-LEHD-fmk (Fig. 3B). However, apigenin abrogated this inhibition and induced the cleavage of caspase-8, caspase-3 and PARP in the presence of Z-IETD-fmk and Z-LEHD-fmk (Fig. 3B). Furthermore, the caspase- 8 and caspase-9 inhibitors did not suppress cell growth, but apigenin was still able to induce apoptosis in their presence (Fig. 3C). These results confirmed that apigenin promoted apoptosis via caspase-dependent mechanisms.

Apigenin decreases cell growth rate of SKBR3 cells via the JAK2-STAT3-VEGF signaling pathway. Whether apigenin regulated the levels of p53, BCL2 and BAX was subsequently evaluated. As indicated in Fig. 4A, apigenin did not influence the expression of p53, BCL2 or BAX. However, apigenin downregulated the expression levels of p-STAT3, p-JAK2 (an upstream kinase of STAT3) and VEGF in SKBR3 cells (Fig. 4B). In addition, apigenin suppressed the expression of p-STAT3 and Hif-1 $\alpha$, which were upregulated by hypoxia mimic $\mathrm{CoCl}_{2}$ (Fig. 4C). Immunocytochemical staining indicated that apigenin decreased the nuclear localization of STAT3 in the presence and absence of $\mathrm{CoCl}_{2}$ (Fig. 5A). Of 
note, apigenin significantly attenuated the $\mathrm{CoCl}_{2}$-induced upregulation of VEGF (Fig. 5B). These results suggested that apigenin decreased the cell growth rate via inhibition of the JAK2-STAT3-VEGF signaling pathway.

S31-201 inhibits cell growth and expression of oncogenic molecules in SKBR3 cells. Whether the STAT3 inhibitor S31-201 inhibited cell proliferation and STAT3 activation in SKBR3 cells was also investigated. As indicated in Fig. 6A and B, S31-201 decreased cell growth in a dose- and time-dependent manner. Furthermore, S31-201 reduced the expression levels of p-STAT3 and VEGF (Fig. 6C). These results demonstrated that STAT3 inhibition induced cell growth inhibition and suppressed the expression of oncogenic molecules.

\section{Discussion}

The present study aimed to evaluate the potential anti-proliferative activity of apigenin in SKBR3 HER2-overexpressing breast cancer cells, and elucidate its mechanism of action (Fig. 7). Apigenin suppressed the growth of SKBR3 cells in a dose- and time-dependent manner. Apigenin also inhibited the growth of papillary and anaplastic thyroid cancer cells (SNU790 and SNU80) in a dose-dependent manner, which suggested that the anti-proliferative effect of apigenin was not limited to breast cancer cells.

The results of the present study indicated that the growth inhibition induced by apigenin was associated with an increase in the sub- $\mathrm{G}_{0} / \mathrm{G}_{1}$ apoptotic population of SKBR3 cells. Apigenin increased the number of apoptotic cells in a dose-dependent manner, as revealed by fluorescence-assisted cell sorting analysis. Of note, apigenin induced apoptosis via caspase-dependent pathways by enhancing the cleavage of caspase-8, caspase- 3 and PARP. In order to determine whether apigenin-induced apoptosis occured via a caspase-8- and caspase-3-dependent pathway, SKBR3 cells were treated with caspase-8 inhibitor Z-IETD-fmk and the caspase-9 inhibitor Z-LEHD-fmk and the expression of caspase-pathway associated factors was evaluated by western blot analysis. It was revealed that the cleavage of caspase-8, caspase- 3 and PARP was inhibited by the caspase- 8 and caspase-9 inhibitors. However, this inhibition was abrogated by apigenin, suggesting that it is a potent inducer of apoptosis.

Caspases are members of a cysteine-dependent aspartate-regulated protease family, frequently associated with cell death (31). Caspases are initially synthesized as relatively inactive zymogens, which are subsequently activated by scaffold-mediated transactivation or cleavage by upstream proteases in the relevant intracellular cascade (31). Following activation, the caspases cleave various intracellular polypeptides, including major cytoplasmic and nucleic structural elements, components of the DNA repair machinery and numerous protein kinases (31).

The results of the western blot analyses in the present study revealed that apigenin did not influence the expression levels of apoptotic molecules, including p53, BCL2 and BAX, which suggested that apigenin may not be able to regulate the levels of p53 (32). However, apigenin reduced the expression of p-STAT3 and p-JAK2 in SKBR3 cells. The VEGF promoter contains various transcription factor binding sites, including sites for STAT3 (33) and Hif-1 (34). The physical interaction between STAT3 and Hif-1 regulates the transcriptional activation of
VEGF via their binding to the VEGF promoter (35). In the present study, it was demonstrated that apigenin inhibited VEGF expression and production, as well as p-STAT3 expression and nuclear localization in the presence or absence of $\mathrm{CoCl}_{2}$. The STAT3 inhibitor S31-201 decreased the expression of p-STAT3 and VEGF. Culturing of SKBR3 cells under conditions that mimicked hypoxia or normoxia did not induce the expression or activation of MMP-2 or MMP-9 (data not shown), as indicated in a previous study (36). Conversely, the co-culture of SKBR3 with another cell line or tumor-associated macrophages induces the expression and activation of MMP-2 and MMP-9 (36). The results of the present study demonstrated that apigenin suppressed cell growth via inhibition of the STAT3-VEGF signaling pathway in SKBR3 cells (Fig. 7).

STAT3 is a transcription factor which modulates gene expression in response to certain cellular stimuli and has significant roles in the mediation of cell growth and apoptosis. STAT3 frequently functions as a tumor promoter; however, a tumor-suppressor role for STAT3 has also been reported $(37,38)$. STAT3 enhances cellular proliferation and angiogenesis, inhibits apoptosis and promotes invasion and metastasis (39-41). The expression of STAT3 in melanoma tumors is associated with poor prognosis (39-41). Constitutive STAT3 phosphorylation is regulated by upstream kinases (Jak and Src) and has been suggested to be a crucial stage in oncogenesis $(42,43)$. Resveratrol (a phytoestrogen) has been shown to inhibit STAT3 signaling and induce apoptosis in malignant cells expressing activated STAT3 (44).

HER2 overexpression is associated with $\sim 20-25 \%$ of invasive breast carcinomas (45). A normal, healthy breast cell has 20,000 HER2 receptors, compared with up to 1.5 million in a breast cancer cell. HER2 is a member of the HER/ErbB2/Neu protein family, which comprises multiple receptors, including HER1/EGFR, HER3 and HER4. Crosstalk between the HER2 and estrogen receptor (ER) signal transduction pathways has been identified (46), and ER is able to modulate HER2 expression levels. In the present study, it was demonstrated that apigenin was able to significantly inhibit the growth of HER2-overexpressing breast cancer cells. This result revealed that apigenin may represent a potential natural therapeutic for the treatment and prevention of HER2-overexpressing breast cancer.

\section{Acknowledgements}

The present study was supported by the Basic Science Research Program through the National Research Foundation of Korea (NRF) funded by the Ministry of Education, Science and Technology (NRF-2012R1A1A3004797). This study was also supported by a grant from the Korean Medicine R\&D project of the Ministry of Health and Welfare (B120014).

\section{References}

1. Shukla S and Gupta S: Apigenin: A promising molecule for cancer prevention. Pharm Res 27: 962-978, 2010.

2. Rezai-Zadeh K, Ehrhart J, Bai Y, Sanberg PR, Bickford P, Tan J and Shytle RD: Apigenin and luteolin modulate microglial activation via inhibition of STAT1-induced CD40 expression. J Neuroinflammation 5: 41, 2008.

3. Moon DO, Kim MO, Choi YH, Lee HG, Kim ND and Kim GY: Gossypol suppresses telomerase activity in human leukemia cells via regulating hTERT. FEBS Lett 582: 367-373, 2008. 
4. Nakazawa T, Yasuda T, Ueda J and Ohsawa K: Antidepressant-like effects of apigenin and 2,4,5-trimethoxycinnamic acid from Perilla frutescens in the forced swimming test. Biol Pharm Bull 26: 474-480, 2003

5. Hashemi M, Nouri Long M, Entezari M, Nafisi S and Nowroozii H: Anti-mutagenic and pro-apoptotic effects of apigenin on human chronic lymphocytic leukemia cells. Acta Med Iran 48: 283-288, 2010.

6. Patel D, Shukla S and Gupta S: Apigenin and cancer chemoprevention: progress, potential and promise (review). Int J Oncol 30: 233-245, 2007.

7. Shukla S and Gupta S: Molecular targets for apigenin-induced cell cycle arrest and apoptosis in prostate cancer cell xenograft. Mol Cancer Ther 5: 843-852, 2006.

8. Liang YC, Huang YT, Tsai SH, Lin-Shiau SY, Chen CF and Lin JK: Suppression of inducible cyclooxygenase and inducible nitric oxide synthase by apigenin and related flavonoids in mouse macrophages. Carcinogenesis 20: 1945-1952, 1999.

9. Birt DF, Mitchell D, Gold B, Pour P and Pinch HC: Inhibition of ultraviolet light induced skin carcinogenesis in SKH-1 mice by apigenin, a plant flavonoid. Anticancer Res 17: 85-91, 1997.

10. Seo HS, Ju JH, Jang K and Shin I: Induction of apoptotic cell death by phytoestrogens by up-regulating the levels of phospho-p53 and $\mathrm{p} 21$ in normal and malignant estrogen receptor $\alpha$-negative breast cells. Nutrition Res 31: 139-146, 2011.

11. Lu HF, Chie YJ, Yang MS, Lee CS, Fu JJ, Yang JS, Tan TW, Wu SH, Ma YS, Ip SW and Chung JG: Apigenin induces caspase-dependent apoptosis in human lung cancer A549 cells through Bax- and Bcl-2-triggered mitochondrial pathway. Int J Oncol 36: 1477-1484, 2010.

12. Wang W, Heideman L, Chung CS, Pelling JC, Koehler KJ and Birt DF: Cell-cycle arrest at $\mathrm{G} 2 / \mathrm{M}$ and growth inhibition by apigenin in human colon carcinoma cell lines. Mol Carcinog 28 : 102-110, 2000.

13. Turktekin M, Konac E, Onen HI, Alp E, Yilmaz A and Menevse S: Evaluation of the effects of the flavonoid apigenin on apoptotic pathway gene expression on the colon cancer cell line (HT29). J Med Food 14: 1107-1117, 2011.

14. Gupta S, Afaq F and Mukhtar H: Involvement of nuclear factor-kappa B, Bax and Bcl-2 in induction of cell cycle arrest and apoptosis by apigenin in human prostate carcinoma cells. Oncogene 21: 3727-3738, 2002.

15. Ruela-de-Sousa RR, Fuhler GM, Blom N, Ferreira CV, Aoyama H and Peppelenbosch MP: Cytotoxicity of apigenin on leukemia cell lines: implications for prevention and therapy. Cell Death Dis 1: e19, 2010.

16. Ujiki MB, Ding XZ, Salabat MR, Bentrem DJ, Golkar L, Milam B, Talamonti MS, Bell RH Hr, Iwamura T and Adrian TE: Apigenin inhibits pancreatic cancer cell proliferation through G2/M cell cycle arrest. Mol Cancer 5: 76, 2006.

17. Fan TJ, Han LH, Cong RS and Liang J: Caspase family proteases and apoptosis: Acta Biochim Biophys Sin (Shanghai) 37: 719-727, 2005

18. Bosch M, Poulter NS, Vatovec S and Franklin-Ton VE: Initiation of programmed cell death in self-incompatibility: role for cytoskeleton modifications and several caspase-like activities. Mol Plant 1: 879-887, 2008.

19. Zhang A, Wu Y, Lai HWL and Yew DT: Apoptosis-a brief review. Neuroembryology 3: 47-59, 2004.

20. Waring $P$ and Mullbacher A: Cell death induced by the Fas/Fas ligand pathway and its role in pathology. Immunol Cell Biol 77: 312-317, 1999.

21. Gupta S: Molecular signaling in death receptor and mitochondrial pathways of apoptosis (review). Int J Oncol 22: 15-20, 2003.

22. Green DR and Reed JC: Mitochondria and apoptosis. Science 281: $1309-1312,1998$

23. Boulares AH, Yakovlev AG, Ivanova V, Stoica BA, Wang G, Iyer S and Smulson M: Role of poly(ADP-ribose) polymerase (PARP) cleavage in apoptosis. Caspase 3-resistant PARP mutant increases rates of apoptosis in transfected cells. J Biol Chem 274: 22932-22940, 1999.

24. Wilson CA, Cajulis EE, Green JL, Olsen TM, Chung YA, Damore MA, Dering J, Calzone FJ and Slamon DJ: HER-2 overexpression differentially alters transforming growth factor-beta responses in luminal versus mesenchymal human breast cancer cells. Breast Cancer Res 7: R1058-R1079, 2005.

25. Prat A, Carey LA, Adamo B, Vidal M, Tabernero J, Cortés J, Parker JS, Perou CM and Baselga J: Molecular features and survival outcomes of the intrinsic subtypes within HER2-positive breast cancer. J Natl Cancer Inst 106: dju152, 2014.
26. Joshi JP, Brown NE, Griner SE and Nahta R: Growth differentiation factor 15 (GDF15)-mediated HER2 phosphorylation reduces trastuzumab sensitivity of HER2-overexpressing breast cancer cells. Biochem Pharmacol 82: 1090-1099, 2011.

27. Favoni RE, Daga A, Malatesta P and Florio T: Preclinical studies identify novel targeted pharmacological strategies for treatment of human malignant pleural mesothelioma. Br J Pharmacol 166: $532-553,2012$.

28. Tokunaga E, Oki E, Nishida K, Koga T, Egashira A, Morita M, Kakeji Y and Maehara Y: Trastuzumab and breast cancer: Developments and current status. Int J Clin Oncol 11: 199-208, 2006.

29. Dean-Colomb W and Esteva FJ: Her2-positive breast cancer: Herceptin and beyond. Eur J Cancer 44: 2806-2812, 2008.

30. Seo HS, Choi HS, Kim SR, Choi YK, Woo SM, Shin I, Woo JK, Park SY, Shin YC and Ko SG: Apigenin induces apoptosis via extrinsic pathway, inducing p53 and inhibiting STAT3 and NFKB signaling in HER2-overexpressing breast cancer cells. Mol Cell Biochem 366: 319-334, 2012.

31. Earnshaw WC, Martins LM and Kaufmann SH: Mammalian caspases: structure, activation, substrates and functions during apoptosis. Annu Rev Biochem 68: 383-424, 1999.

32. Blagosklonny MV, An WG, Romanova LY, Trepel J, Fojo T and Neckers L: p53 inhibits hypoxia-inducible factor-stimulated transcription. J Biol Chem 273: 11995-11998, 1998

33. Niu G, Wright KL, Huang M, Song L, Haura E, Turkson J, Zhang S, Wang T, Sinibaldi D, Coppola D, Heller R, Ellis LM, Karras J, Bromberg J, Pardoll D, Jove R and Yu H: Constitutive Stat3 activity up-regulates VEGF expression and tumor angiogenesis. Oncogene 21: 2000-2008, 2002.

34. Forsythe JA, Jiang BH, Iyer NV, Agani F, Leung SW, Koos RD and Semenza GL: Activation of vascular endothelial growth factor gene transcription by Hypoxia-inducible factor 1 . Mol Cell Biol 16: 4604-4613, 1996.

35. Jung JE, Lee HG, Cho IH, Chung DH, Yoon SH, Yang YM, Lee JW, Choi S, Park JW, Ye SK and Chung MH: STAT3 is a potential modulator of HIF-1-mediated VEGF expression in human renal carcinoma cells. FASEB J 19: 1296-1298, 2005.

36. Hagemann T, Robinson SC, Schulz M, Trümper L, Balkwill FR and Binder C: Enhanced invasiveness of breast cancer cell lines upon co-cultivation with macrophages is due to TNF-alpha dependent up-regulation of matrix metalloproteases. Carcinogenesis 25: 1543-1549, 2004.

37. de la Iglesia N, Konopka G, Puram SV, Chan JA, Bachoo RM, You MJ, Levy DE, DEPinho RA and Bonni A: Identification of a PTEN-regulated STAT3 brain tumor suppressor pathway. Genes Dev 22: 449-462, 2008

38. Lewis HD, Winter A, Murphy TF, Tripathi S, Pandey VN and Barton BE: STAT3 inhibition in prostate and pancreatic cancer lines by STAT3 binding sequence oligonucleotides: Differential activity between 5' and 3' ends. Mol Cancer Ther 7: 1543-1550, 2008.

39. Kortylewski M, Jove R and Yu H: Targeting STAT3 affects melanoma on multiple fronts. Cancer Metastasis Rev 24: 315-327, 2005.

40. Niu G, Bowman T, Huang M, Shivers S, Reintgen D, Daud A, Chang A, Kraker A, Jove R and Yu H: Roles of activated Src and Stat3 signaling in melanoma tumor cell growth. Oncogene 21: 7001-7010, 2002

41. Xie TX, Huang FJ, Aldape KD, Kang SH, Liu M, Gershenwald JE, Xie K, Sawaya R and Huang S: Activation of stat3 in human melanoma promotes brain metastasis. Cancer Res 66: 3188-3196, 2006.

42. Sellers LA, Feniuk W, Humphrey PP and Lauder H: Activated $\mathrm{G}$ proteincoupled receptor induces tyrosine phosphorylation of STAT3 and agonist-selective serine phosphorylation via sustained stimulation of mitogen-activated protein kinase. Resultant effects on cell proliferation. J Biol Chem 274: 16423-16430, 1999.

43. Zhang Y, Turkson J, Carter-Su C, Smithgall T, Levitzki A, Kraker A, Krolewski JJ, Medveczky P and Jove R: Activation of Stat 3 in $\mathrm{v}$-Src-transformed fibroblasts requires cooperation of Jak1 kinase activity. J Biol Chem 275: 24935-24944, 2000.

44. Kotha A, Sekharam M, Cilenti L, Siddiquee K, Khaled A, Zervos AS, Carter B, Turkson J and Jove R: Resveratrol inhibits src and Stat 3 signaling and induces the apoptosis of malignant cells containing activated Stat 3 protein. Mol Cancer Ther 5: 621-629, 2006

45. Tolaney SM and Krop IE: Mechanisms of trastuzumab resistance in breast cancer. Anticancer Agents Med Chem 9: 348-355, 2009.

46. Buzdar AU: Role of biologic therapy and chemotherapy in hormone receptor- and HER2-positive breast cancer. Ann Oncol 20: 993-999, 2009. 